\author{
이 승 주* \\ 세종대학교 조리외식경영학과

\section{Exploratory Study on the Quality Grade of Korea Black Raspberry Wines by Using Consumer Preference Data}

\author{
Seung-Joo Lee* \\ Department of Culinary and Food Service Management, Sejong University
}

\begin{abstract}
In this study, 100 consumers (men, 50; women, 50; age group, 20-50 years) rated their overall preferences for 24 Korean raspberry wines by using a 9-point hedonic scale. The analysis of variance was constructed to evaluate the effect of gender, age, and samples on the preference scores of the wine products. Significant differences were observed in overall preferences for the 24 samples; however, no interactions based on preferences by age and gender groups were noted. Cluster analysis was performed to determine sample clustering based on the frequencies from the preference data. Three clusters were obtained; these three clusters were well separated based on the mean overall preference scores for the samples. Discriminant analysis based on the three clusters also confirmed the same grouping of samples with $100 \%$ accuracy.
\end{abstract}

Keywords: Korean black raspberry wine, preference, classification, discriminant analysis, quality

\section{서 론}

식품에 있어서 품질은 매우 다면적인 특성을 가지고 있다. 식 품의 품질을 결정하는 요소로는 기본적인 관능특성 뿐 아니라 안 전성(safety), 영양(nutrition)과 외부적 요인으로 브랜드, 가격, 원 산지 등이 있다. 이러한 다양한 품질요소 중 특히 식품의 관능적 품질(sensory quality)은 소비자들이 직접 인지하는 가장 중요한 품질 특성 중 하나라 할 수 있다(1). 이러한 식품의 관능적 품질 특성을 파악하기 위해 다양한 분석방법이 적용되어 왔다 $(2,3)$. 과 거 주류나 낙농, 축산업계에서는 관능적 품질평가에, 주로 완제 품의 결함여부에 집중한 전문가 평가법이 적용되었다(4-6). 또한 일부 훈련된 패널을 활용하여 주요 관능특성에 대한 정량적 분 석을 실시하거나(4), 기기분석 결과와 함께 제시되기도 하였다. 그러나 최근에는 일부 전문가나 훈련된 패널의 평가 결과가 실 제 제품을 구매하고 소비하는 소비자의 의견과 상충되는 결과가 다수 보고되어 논란이 되고 있다 $(6,7)$. 따라서 소비자의 지각된 품질(perceived quality)을 품질평가나 품질관리에 반영해야 한다 는 의견이 대두되고 있으며(2), 실제 다양한 식육 제품과 과일, 채소의 품질 평가에서 소비자의 의견이 가장 중요한 요소로 보 고된 바 있다(8-10).

따라서 다양한 식품의 품질평가에 소비자가 평가한 기호도

*Corresponding author: Seung-Joo Lee, Department of Culinary and Food Service Management, Sejong University, Seoul 143-147, Korea

Tel: $82-2-3408-3187$

Fax: 82-2-3408-4313

E-mail: sejlee@sejong.ac.kr

Received February 3, 2014; revised February 14, 2014; accepted February 18, 2014 (preference)나 품질(quality)이 품질규격 확립이나 평가시스템 개 발에 활용되고 있다. 아랍에서 널리 소비되는 디저트인 fruits dates (Tamr)의 총체적 품질평가시스템 개발에서 소비자 조사를 통해 품질 기준과 규격을 수립하였고, 이를 바탕으로 수행한 패널 품 질평가결과와 소비자 기호도 조사 결과가 일치하는 것으로 나타 났다(8). 식육의 품질평가에도 기존의 다른 식품과 유사하게 훈 련된 패널(전문가 등)을 활용한 관능평가, 기기분석 등이 활용되 었다. 기기분석의 경우 간단하고, 저비용에 재현성이 있는 결과 를 도출할 수 있으나 복합적인 품질요소에 대한 평가가 다면적 으로 이루어지기 어려운 측면이 있다. 식육의 기기분석치와 관능 검사와의 관계를 파악한 결과 shear force가 sensory tenderness의 가장 적합한 예측 항목으로 평가되었으나, 다양한 처리나 저장 숙성시의 차이를 파악하는 데는 한계를 나타내었다 $(11,12)$. 결과 적으로 일부 기기분석치가 tenderness나 juiciness 같은 식육 평가 시 주요한 관능적 품질 평가 항목과 높은 상관관계를 나타내었 으나, 이를 통합적인 품질평가(overall quality score)나 소비자 만 족도(consumer satisfaction)로의 활용에는 한계를 보여 왔다(13). 이러한 연구결과에 따라 호주의 식육협회에서는 기존의 전문가 나 기기분석을 활용한 품질 등급 평가(Meat Standards Australia) 를 소비자 기호도 조사를 활용한 방법으로 변경한 바 있다(11). 이러한 품질 평가시스템은 일본과 국내에서 식육의 품질평가에 도 다양하게 적용되고 있다 $(3,14,15)$.

국내에서 생산되는 과실주로는 복분자주를 비롯해 머루주·포 도주·오디주 등이 있으나 복분자주가 가장 높은 시장 점유율을 차지하고 있다(16). 복분자주의 경우 1990년대 후반 고창군 일대 의 대규모 복분자 재배에 따라 개발되었으며, 이후 시장 확대에 따라 2004년 이후 다양한 중견기업이 진출하였다. 2008년 약 1800 억 원대로 시장규모가 성장하였으나 이후 막걸리의 시장 확대에 따라 최근에는 주춤한 편이다. 그러나 복분자주는 와인과 같이 
Table 1. Korean black raspberry wines (bokbunjaju) and their manufacturing places $(\mathrm{N}=\mathbf{2 4})$

\begin{tabular}{cccccl}
\hline Code & $\begin{array}{c}\text { Alcohol content } \\
(\%)\end{array}$ & Manufacturing places & Code & $\begin{array}{c}\text { Alcohol content } \\
(\%)\end{array}$ & \multicolumn{1}{c}{ Manufacturing places } \\
\hline KO & 13 & Jeollabuk-do Gochang-gun & NJ & 16 & Jeollabuk-do Jeongeup-si \\
SW & 16 & Jeollabuk-do Gochang-gun & MO & 12 & Jeollabuk-do Gimje-si \\
BA & 12 & Jeollabuk-do Gochang-gun & BB & 16 & Jeollanam-do Damyang-si \\
GO & 15 & Jeollabuk-do Gochang-gun & BH & 15 & Jeollanam-do Mokpo-si \\
SU & 16 & Jeollabuk-do Gochang-gun & HP & 15 & Jeollanam-do Hampyeong-gun \\
MY & 17 & Jeollabuk-do Gochang-gun & GJ & 16 & Jeollanam-do Gwangju-si \\
SE & 16 & Jeollabuk-do Gochang-gun & JI & 16 & Gyeongsangnam-do Hamyang-gun \\
DO & 16 & Jeollabuk-do Gochang-gun & HY & 16 & Gyeongsangnam-do Hamyang-gun \\
CO & 15 & Jeollabuk-do Gochang-gun & DW & 16 & Gangwon-do Pyeongchang-gun \\
NB & 15 & Jeollabuk-do Buan-gun & SR & 16 & Gangwon-do Hongcheon-gun \\
SB & 16 & Jeollabuk-do Jeonju-si & CH & 15 & Chungcheongnam-do Cheongyang-gun \\
SC & 13 & Jeollabuk-do Sunchang-gun & HB & 15 & Jeju-do Jeju-si \\
\hline
\end{tabular}

각종 건강 기능성이 보고되어(17) 향후 와인과 함께 저도주 위주 의 주류시장에서 주요한 과실주로 자리매김할 것으로 여겨진다. 현재 복분자주는 중견기업에서 영세한 민속주 업체까지 다양한 기업에서 생산되고 있다. 그러나 국내 생산 주요 과실주인 복분 자주에 대해 소비자들이 인지하는 기호도 수준에 대한 정확히 조 사가 이루어지지 못하고 있다. 향후 시장 확대와 소비자 인지도 제고를 위해서는 올바른 소비자 기호도 조사와 향후 이를 바탕 으로 한 총체적 품질평가시스템 확립이 필요한 것으로 여겨진다. 본 연구에서는 전국에서 시판되는 복분자주 24 종을 수거하여 소 비자 기호도 평가를 실시하였으며, 이를 바탕으로 군집분석과 판 별분석을 활용하여 복분자주의 탐색적 품질 등급을 살펴보았다. 이를 국내 주요 과실주인 복분자주의 품질 평가시스템 개발을 위 한 기초자료로 활용하고자 한다.

\section{재료 및 방법}

재료

본 연구에 사용된 복분자주는 2008년 6월 전국의 대형 할인매 장, 주류도매상, 우편판매책자 등을 통해 국내에 시판되는 복분 자주 중 지역별 특성과 매출수준을 고려하여 24종을 선발하여 사 용하였다. 모든 제품의 주종은 과실주로 일부 시판되는 기존의 복분자를 첨가한 탁주는 포함하지 않았다. 연구에 사용된 복분자 주 관련 사항은 Table 1과 같다.

\section{소비자 기호도 조사}

일반 주류 소비자를 모집하여 복분자주 제품에 대한 소비자 기 호도 조사를 실시하였다. 소비자는 일반 주류소비자 중 성별, 연 령을 고려하여 편의추출을 이용하여 총 100 명의 소비자(남 50 명, 여 50명: 20-30대: 60명, 40-50대: 40명)를 모집하였다. 기호도 조 사에 참여한 소비자의 일반사항은 Table 2 와 같다.

복분자주의 전반적인 품질을 제품을 최종적으로 소비하고 구 매하는 소비자의 기호도로 가정하여 전체적인 기호도 조사를 실 시하였다. 전체적인 기호도 항목은 9점 기호 척도(1점: 대단히 싫 다, 5점: 좋지도 싫지도 않다, 9점: 대단히 좋다)에 의해 평가하 였다. 시료는 세 자리 난수표로 코드화되어 투명한 플라스틱 컵 에 상온 $\left(18-21^{\circ} \mathrm{C}\right)$ 으로 제시되었다. 제시된 시료는 Williams' latin square 법에 의해 랜덤화되어 순서상의 오차를 최소화하였다(18). 24 개 시료의 실험을 위해 이틀에 걸쳐 실시하였고, 한 세션에서
Table 2. General characteristics of the subjects $(N=100)$

\begin{tabular}{clcc}
\hline & Category & Frequency & $\%$ \\
\hline \multirow{2}{*}{ Gender } & Male & 50 & 50 \\
& Female & 50 & 50 \\
\hline \multirow{3}{*}{ Age (yrs) } & $20-29$ & 37 & 37 \\
& $30-39$ & 23 & 23 \\
& $40-49$ & 25 & 25 \\
& $50-59$ & 15 & 15 \\
\hline & student & 5 & 5 \\
Occupation & office worker & 43 & 43 \\
& professional & 44 & 44 \\
& not work & 7 & 7 \\
& other & 1 & 1 \\
\hline Average & under 100 & 3 & 3 \\
salary per & $101-200$ & 31 & 31 \\
month & $201-300$ & 7 & 7 \\
(unitW10,000) & $301-400$ & 16 & 16 \\
& $401-500$ & 22 & 22 \\
& over 501 & 21 & 21 \\
\hline
\end{tabular}

는 6개의 랜덤화된 시료가 소비자에게 제시되었다. 하나의 세션 이 완료된 후 20 분간의 휴식 시간을 갖고 다음 세션을 진행하여 하루에 12 개의 시료에 대한 평가를 실시하였다. 입가심용 물과 식빵을 함께 제공하였다. 소비자 기호도 평가 장소는 세미나실에 서 소비자간 거리를 두어 방해받지 않도록 한 상태에서 진행하였다.

\section{통계분석}

소비자 기호도 조사 결과를 바탕으로, 각각의 기호도 조사항목 의 제품 간 차이를 파악하기 위해 분산분석(analysis of variance) 을 실시하였다. 시료(sample), 연령(age), 성별(gender), 소비자(consumer)를 주요인(factor)으로 하고 성별x시료, 연령×시료, 성별×연 령간의 교호작용(interaction)을 파악하였다. 소비자가 직접 시음하 고 평가한 기호도 테이터를 바탕으로 계층적 군집분석(hierarchical cluster analysis)을 적용하여 24개 복분자주의 군집을 구분하였다. 군집분석 결과 구분된 세 개의 군집을 바탕으로 판별분석(discriminant analysis)을 적용하여 군집 간의 분류를 확인하고 예측력을 
Table 3. F-ratios from the ANOVA procedure applied to the hedonic ratings of Korean black raspberry wines (bokbunjaju) $(\mathrm{N}=\mathbf{1 0 0})$

\begin{tabular}{lcc}
\hline \multirow{2}{*}{ Source of variation } & $\begin{array}{c}\text { Degree of } \\
\text { freedom }\end{array}$ & F-ratios \\
\cline { 3 - 3 } & 96 & Overall linking \\
\hline Consumer & 23 & $5.66^{* * * *}$ \\
Sample & 1 & $8.12^{* * * *}$ \\
Age & 1 & $3.91^{*}$ \\
Gender & 23 & $7.73^{* *}$ \\
Gender $\times$ Sample & 23 & $0.79^{*}$ \\
Age $\times$ Sample & 1 & $1.18^{*}$ \\
Gender $\times$ Age & & $6.56^{*}$ \\
\hline
\end{tabular}

${ }^{*} p<0.05,{ }^{* *} p<0.01,{ }^{* * * *} p<0.0001$

검증하였다. 판별함수는 선형 판별함수를 사용하였다. 통계분석 은 SAS for Windows 7.2 (SAS Institute, Cary, NC, USA)와 XLSTAT ver. 2007.1 (Addinsoft, New York, NY, USA)를 이용하 여 실시하였다.

\section{결과 및 고찰}

\section{소비자 기호도 조사}

24개의 복분자주 시료에 대해 시료의 브랜드와 가격에 대한 정보가 없는 상태에서 시료의 전체적인 기호도를 조사하였다. 기호도 평가 항목에 대한 분산분석 결과는 Table 3 과 같다. 기 호도 평가 항목에서 소비자(consumer), 시료(sample)간의 유의적 차이가 확인되었다 $(p<0.0001)$. 전체적인 기호도 평가를 살펴보 면, 각각 연령(20-30대 vs 40-50대)별, 남녀(gender)별 다른 평가 가 이루어졌으나(각각 $p<0.05, p<0.01$ ), 시료별 평가간의 연령 (age×sample)과 성별(gender×sample)에 따른 교호작용은 나타나 지 않아 시료 평가는 연령 및 성별간의 차이 없이 유사한 평가 경향을 나타낸 것으로 여겨진다. 이러한 결과는 소비자 조사에 서 다수 보고된 바 있으며 연령과 성별에 따른 차이보다는 개 인 간의 차이가 더 크게 시료의 기호도 평가에 영향을 주는 것 으로 여겨진다(19-21)

24 개의 복분자주 시료의 100 명 소비자의 기호도 조사 결과 평 균값과 Fisher least significant difference (LSD)는 Table 4와 같다 . 기호도 조사 결과 전체적인 기호도 항목에서 가장 높은 점수를 받은 시료는 $\mathrm{SR}$ 로 나타났고, $\mathrm{KO}, \mathrm{BH}$ 가 그 뒤를 이었다. 소비자 조사에 참가한 남녀, 연령대별로 전체적인 기호도 평가를 분석한 결과는 Fig. 1과 같다. SR은 20-50대 남, 여 모든 패널에게서 다 른 시료보다 높은 점수를 받았으며 특히 40-50대(6.15점)의 경우 다른 시료보다 높은 점수를 나타냄을 알 수 있다. 40-50대의 경 우 SR과 SE제품이 높은 점수를 나타내었고, 20-30대의 경우 SR, $\mathrm{BH}, \mathrm{KU}$ 의 순으로 높은 점수를 나타내었다. 남녀의 성비별로 살 펴보면 남자의 경우 $\mathrm{SR}, \mathrm{KU}$ 의 순으로 여자의 경우 $\mathrm{SR}, \mathrm{BH}, \mathrm{KU}$ 순으로 높은 점수를 나타내었다. 일부 시료에서 연령 및 남녀별 약간의 차이를 나타내었으나 전반적인 기호도 평가 순위는 전체 소비자 합과 유사한 경향을 나타내었다.

\section{소비자 기호도를 바탕으로 한 군집 분류}

일차적으로 100 명 소비자의 각 시료별 9점 기호척도 원점수와 기호 척도별 빈도수의 두 개 데이터를 바탕으로 군집분석을 실 시하였다. 안정적인 군집 분류를 보이고 군집간의 유의적 기호도
Table 4. Mean scores $^{1}$ of preference test for Korean black raspberry wines (bokbunjaju) $(\mathrm{N}=100)$

\begin{tabular}{cc}
\hline Sample code & Overall preference ${ }^{2}$ \\
\hline SR & $5.96^{\mathrm{a}}$ \\
KO & $5.70^{\mathrm{ab}}$ \\
BH & $5.61^{\mathrm{abc}}$ \\
MO & $5.47^{\mathrm{bcd}}$ \\
SW & $5.47^{\mathrm{bcd}}$ \\
DO & $5.41^{\mathrm{bcd}}$ \\
SC & $5.35^{\mathrm{bcde}}$ \\
NJ & $5.28^{\mathrm{bcde}}$ \\
HP & $5.25^{\mathrm{cde}}$ \\
SE & $5.21^{\mathrm{cdef}}$ \\
HY & $5.16^{\mathrm{def}}$ \\
SB & $5.10^{\mathrm{def}}$ \\
CO & $5.09^{\mathrm{def}}$ \\
BA & $5.06^{\mathrm{def}}$ \\
JI & $5.06^{\mathrm{def}}$ \\
HB & $5.05^{\mathrm{def}}$ \\
GO & $5.05^{\mathrm{def}}$ \\
CH & $4.94^{\mathrm{efg}}$ \\
MY & $4.94^{\mathrm{efg}}$ \\
DW & $4.80^{\mathrm{ggh}}$ \\
SU & $4.57^{\mathrm{ghi}}$ \\
GJ & $4.44^{\mathrm{hij}}$ \\
BB & $4.20^{\mathrm{ij}}$ \\
NB & $4.06^{\mathrm{j}}$ \\
LSD $(5 \%)$ & 0.44 \\
\hline
\end{tabular}

${ }^{11}$ Means with the same letter in a column are not significantly different at $p<0.05$ level by Fisher's least significant difference (LSD) test.

${ }^{2)} 9$ point hedonic scale (1: extremely dislike, 5: neither dislike or like, 9: extremely like)

평가에서 차이를 뚜렷하게 나타내는 것을 군집 분류의 기준으로 삼았다. 최종적으로 24 종의 복분자주에 대한 소비자의 9점 기호 척도에 대한 빈도수 분포(Table 5)를 바탕으로 계층적 군집분석 (hierarchical cluster analysis based on Euclidean distance and Ward linkage)을 실시하여 기호척도 분포가 유사하게 나타난 시 료들 간의 군집을 확인하였다. 이러한 소비자 기호도 빈도수 데 이터의 활용은 퍼지추론을 이용한 쌀밥의 전체적 기호도 예측연 구(22)에 적용된 바 있다. 24종의 복분자주의 군집 분석 결과의 덴드로그램은 Fig. 2와 같다. 군집 간의 거리를 바탕으로 자동 군 집 선정 툴에 의해 세 개의 군으로 분류되었다. 결과를 살펴보면 $\mathrm{SR}, \mathrm{KO}, \mathrm{BH}, \mathrm{MO}, \mathrm{SW}, \mathrm{DO}, \mathrm{NJ}, \mathrm{SB}, \mathrm{JI}$ 의 9개 제품이 가장 높 은 기호 척도 분포를 보인 것으로 나타났고 다음은 2 군으로 12 개의 시료가 분포하였다. 기호 분포가 가장 낮은 3 군으로는 $\mathrm{BB}$, $\mathrm{GJ}, \mathrm{NB}$ 가 분류되었다. 3 군으로 분류된 시료는 전반적인 소비자 기호도가 떨어지는 것으로 나타나 향후 제품의 품질 개선이 필 요한 것으로 여겨진다. 분석결과 세 군집의 평균값간의 거리를 살펴보면 1 군과 2 군 간의 거리는 11.267 로 나타났고 1 군과 3 군 간의 거리는 25.353 으로 거리가 증가한 것으로 나타났다. 실제 세 군집으로 분류된 각 군집간의 기호도 평가 결과의 차이는 Table 6 과 같다. 군집 1 의 경우 5 점, 6 점, 8 점의 100 명 소비자의 평균 빈도수가 각각 $24.56,21.67,9.67$ 로 세 군집 중 가장 높게 나타났고, 낮은 기호도를 나타내는 1점-4점에서는 세 군집 중 가 장 낮은 빈도를 나타내었다. 실제 군집 1 과 2 의 경우 군집 3 에 


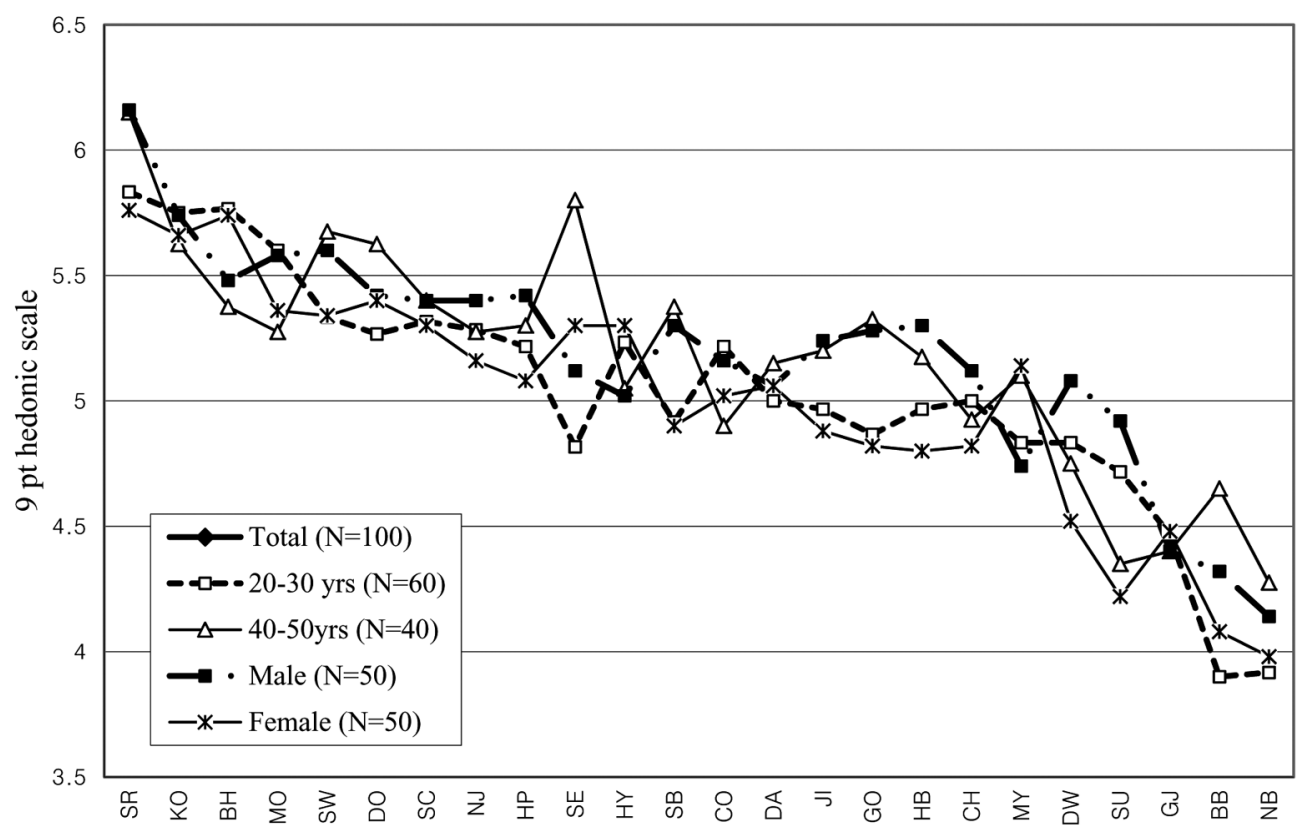

Fig 1. Overall preference scores of Korean black raspberry wines (bokbunjaju) by age and gender groups.

비해 가까운 거리에 있어서 7점과 9점 평균 빈도수에서는 각각 14.11 과 $14.17,2.22$ 와 2.25 로 거의 차이가 없었다. 반면 군집 3 의 경우 다른 군에 비해 2점과 3점의 평균 빈도수가 14.33 과 19.33 으로 매우 높아 다른 군집에 비해 낮은 기호도 평가를 다시 확 인하였다.

\section{기호도 군집을 바탕으로 한 판별분석}

판별분석(discrimination analysis)은 다양한 정보로부터 집단을 구별할 수 있는 판별함수(discriminant function) 또는 판별규칙 (discriminant rule)을 만들고, 새로운 개체에 대해 어느 집단에 속 하는지를 판별하여 분류하는 탐색적인 통계기법이다(23). 본 연

Table 5. Frequencies of each preference rating score by 24 black raspberry wines $(N=100)$

\begin{tabular}{|c|c|c|c|c|c|c|c|c|c|c|}
\hline \multirow{2}{*}{$\begin{array}{l}\text { Sample } \\
\text { code }\end{array}$} & \multirow{2}{*}{$\begin{array}{l}\text { Overall preference } \\
\text { score }\end{array}$} & \multicolumn{9}{|c|}{ Frequency of each 9 point hedonic score } \\
\hline & & 1 & 2 & 3 & 4 & 5 & 6 & 7 & 8 & 9 \\
\hline SR & 5.96 & 1 & 2 & 4 & 13 & 20 & 23 & 13 & 18 & 6 \\
\hline KU & 5.70 & 0 & 1 & 8 & 13 & 22 & 27 & 14 & 13 & 2 \\
\hline $\mathrm{BH}$ & 5.61 & 0 & 1 & 11 & 14 & 24 & 20 & 13 & 14 & 3 \\
\hline MO & 5.47 & 0 & 2 & 6 & 21 & 25 & 18 & 16 & 12 & 0 \\
\hline SW & 5.47 & 0 & 3 & 6 & 23 & 21 & 17 & 19 & 8 & 3 \\
\hline DO & 5.41 & 1 & 4 & 4 & 17 & 26 & 25 & 15 & 5 & 3 \\
\hline $\mathrm{SC}$ & 5.35 & 5 & 1 & 9 & 21 & 14 & 17 & 21 & 10 & 2 \\
\hline NJ & 5.28 & 2 & 5 & 8 & 15 & 25 & 20 & 14 & 10 & 1 \\
\hline HP & 5.25 & 1 & 2 & 12 & 22 & 20 & 19 & 12 & 10 & 2 \\
\hline SE & 5.21 & 2 & 5 & 9 & 25 & 14 & 21 & 12 & 6 & 6 \\
\hline HY & 5.16 & 2 & 5 & 17 & 14 & 17 & 19 & 14 & 8 & 4 \\
\hline SB & 5.10 & 1 & 1 & 11 & 18 & 29 & 27 & 10 & 2 & 1 \\
\hline $\mathrm{CO}$ & 5.09 & 2 & 3 & 13 & 23 & 19 & 11 & 25 & 2 & 2 \\
\hline BA & 5.06 & 2 & 8 & 8 & 20 & 20 & 19 & 16 & 5 & 2 \\
\hline JI & 5.06 & 0 & 5 & 13 & 16 & 29 & 18 & 13 & 5 & 1 \\
\hline $\mathrm{HB}$ & 5.05 & 1 & 4 & 13 & 24 & 17 & 19 & 16 & 4 & 2 \\
\hline GO & 5.05 & 1 & 8 & 10 & 19 & 21 & 20 & 12 & 8 & 1 \\
\hline $\mathrm{CH}$ & 4.94 & 1 & 2 & 11 & 30 & 21 & 19 & 10 & 4 & 2 \\
\hline MY & 4.94 & 3 & 4 & 9 & 26 & 25 & 16 & 8 & 6 & 3 \\
\hline DW & 4.80 & 3 & 4 & 12 & 24 & 26 & 15 & 12 & 3 & 1 \\
\hline SU & 4.57 & 5 & 5 & 13 & 33 & 13 & 15 & 12 & 4 & 0 \\
\hline GJ & 4.44 & 3 & 14 & 23 & 17 & 13 & 13 & 6 & 8 & 3 \\
\hline BB & 4.20 & 4 & 17 & 14 & 27 & 16 & 10 & 6 & 4 & 2 \\
\hline NB & 4.06 & 8 & 12 & 20 & 26 & 13 & 5 & 13 & 3 & 0 \\
\hline
\end{tabular}




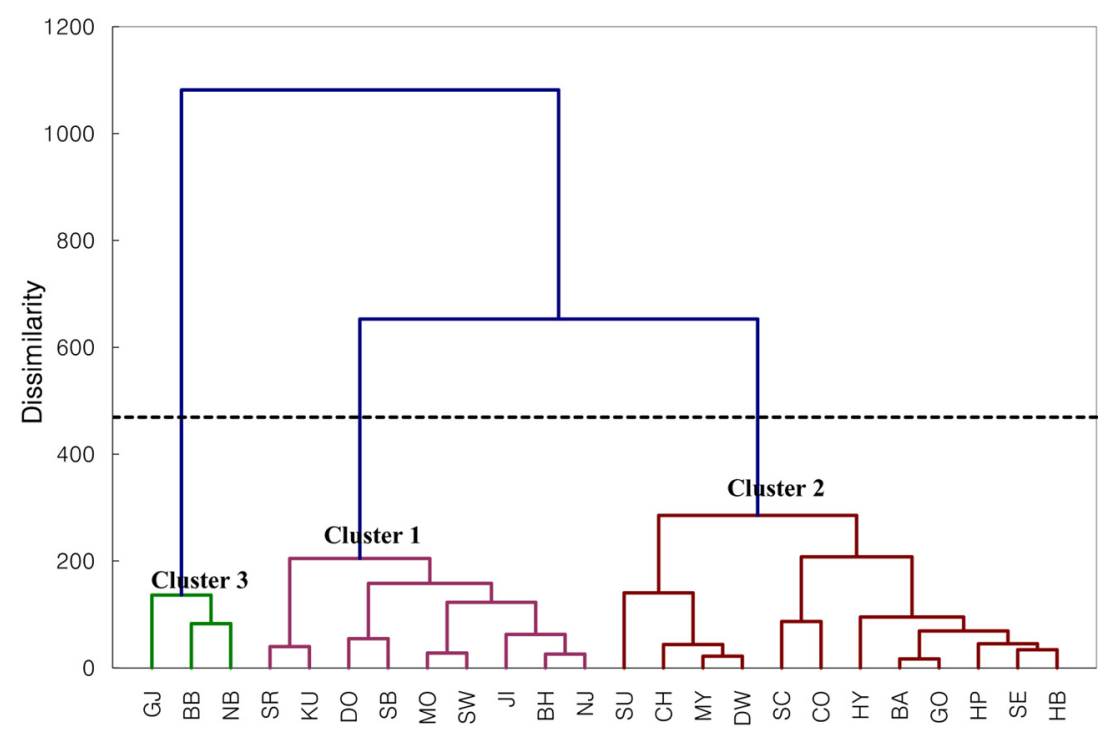

Fig. 2. Dendrogram of 24 black raspberry wines by agglomerative hierarchical clustering (AHC) based on frequencies of hedonic rating scores.

Table 6. General statistics of each cluster determined by frequencies of hedonic rating scores

\begin{tabular}{|c|c|c|c|c|c|c|c|c|c|c|}
\hline & \multicolumn{9}{|c|}{ Mean frequency of each hedonic score in each cluster $(\mathrm{N}=100)$} & \multirow{2}{*}{$\begin{array}{l}\text { Mean overall } \\
\text { preference score with } \\
\text { standard error }\end{array}$} \\
\hline & 1 & 2 & 3 & 4 & 5 & 6 & 7 & 8 & 9 & \\
\hline Cluster $1(\mathrm{~N}=9)$ & 0.56 & 2.67 & 7.89 & 16.67 & 24.56 & 21.67 & 14.11 & 9.67 & 2.22 & $5.45 \pm 0.09$ \\
\hline Cluster $2(\mathrm{~N}=12)$ & 2.33 & 4.25 & 11.33 & 23.42 & 18.92 & 17.50 & 14.17 & 5.83 & 2.25 & $5.04 \pm 0.06$ \\
\hline Cluster $3(\mathrm{~N}=3)$ & 5.00 & 14.33 & 19.00 & 23.33 & 14.00 & 9.33 & 8.33 & 5.00 & 1.67 & $4.23 \pm 0.11$ \\
\hline
\end{tabular}

구에서는 1 차적으로 기호도 조사 결과를 바탕으로 군집분석을 이 용하여 24 개 복분자주를 3 개의 군집(등급)으로 분류하였다. 이러 한 분류 결과를 바탕으로 향후 소비자 기호도 조사 결과를 이용 하여 제품이 어느 집단에 속하는지 판별 가능한지, 예측력은 어 느 정도인지 또한 군집분석 결과가 적정한지 확인하기 위해 판 별분석을 실시하였다. 판별분석에 사용된 독립변수로 1 점에서 9 점까지 9 개의 기호척도 항목의 각 시료별 평균 빈도수가 사용되 었고, 이들 기호척도 항목의 평균 빈도수간의 일변량 분산분석 결과 모든 변수에서 시료 간 매우 유의하였다 $(p<0.0001)$. 또한 이 들 변수들의 다변량 분산분석 결과, Wilks' Lambda값이 0.037 $(p<0.0001)$ 로 그룹간의 평균벡터에 대한 차이가 매우 유의함을 알 수 있다. 따라서 본 판별분석에 세 개 군집간의 유의적인 차 이를 확인할 수 있었다. 세 개 그룹간의 거리를 구하기 위해 합 동공분산을 이용한 마할라노비스거리(Mahalanobis distances)를 살 펴보면, 군집 1 에서 군집 2 간의 거리는 13.42 로 군집 1 과 군집 3 과 의 129.02 에 비해 가까운 것으로 나타났다. 군집 2 와 군집 3 의 거 리는 68.83 으로 전반적으로 군집 1 과 2 가 가깝고 군집 3 의 경우 동 떨어진 것으로 나타났다. 이는 군집분석에서 세 군집간의 거리와 도 유사한 경향을 보였다. 마할라노비스 거리는 분류된 집단 상 호 중심까지의 거리로서 멀수록 그룹 간에 관련성이 적은 것으 로 볼 수 있다(23).

판별함수를 선형이나 2차 함수를 사용할지 결정하기 위해, 각 분류 그룹의 공분산행렬(covariance matrix)의 동일성에 대해 카이 제곱검정을 실시하였다. 검정결과 카이제곱통계량이 $33.93(p>0.05)$ 로 귀무가설을 받아들여 각 그룹의 공분산행렬이 동일하다고 할 수 있으므로 본 연구에서는 선형판별함수를 사용하였다. 이에 따 른 각 군집 별 판별함수를 살펴보면, 세 개 군집에서 모두 기호
도 7점 항목에서는 계수가 0 으로 판별함수에 기여하지 못 하는 것으로 나타났고, 상대적으로 낮은 기호 척도인 1점-4점에서의 빈 도수가 높은 계수를 나타내어 시료를 판별하는데 비중이 높은 것 으로 나타났다. 분류함수의 능력을 판단하는 데는 일반적으로 오 분류(misclassification)의 확률로서 오류율(error rate)과 정확한 분 류율(correct classification)을 이용한다(23). 본 연구에서 판별함수 적용에 따른 분류결과를 살펴보면, 모든 시료에서 판별함수 적용 후 정확한 분류를 하여 $100 \%$ 분류율을 나타내었다. 판별분석 결 과 24개 시료의 분포도는 Fig. 3과 같다. 추출된 첫 번째 요인 (F1)이 전체 데이터에 대한 설명력 $94.33 \%$ 로 1차원적인 모형을 나타내었다. 군집 $1,2,3$ 간의 분류가 F1 상에 분포됨을 확인할 수 있다. 군집 1 의 경우 $\mathrm{F} 1$ 의 가장 왼편으로 분포하였고 다음으로 군집 2의 경우 $\mathrm{F} 1$ 의 가운데 부분에 대개 자리 잡았다. 군집1과 2 간의 거리에 비해 군집 3 의 경우 $\mathrm{F} 1$ 상의 가장 오른편으로 나타 나 마할라노비스거리 분석 결과와 일치하는 것으로 나타났다. 전 반적으로 시료의 군집간의 분류가 적절한 것으로 여겨진다.

국내산 한우의 맛 등급 설정을 위한 연구에도 다양한 판별분 석(정준판별분석, 선형판별분석, 비모수적 판별분석 등)을 활용하 여 소비자 기호도 조사 결과를 바탕으로 등급 분류를 시도한 바 있다(3). 또한 호주에서는 1996년부터 쇠고기 각 부위의 조리방 법을 달리한 시료의 관능검사와 소비자 기호도 조사를 실시하여 데이터베이스를 구축하였고 이를 바탕으로 통합적인 meat quality score (MQ4) 산출을 위해 선형 판별함수를 적용하였다(11). 앞으 로 이러한 소비자들의 직접적인 관능검사나 기호도 조사를 바탕 으로 한 품질평가체계가 복분자주와 같은 다양한 우리술의 평가 에도 적용되어야 할 것으로 여겨진다. 이를 위해 먼저 좀 더 많 은 제품과 소비자를 대상으로 한 데이터베이스 구축이 필요하 


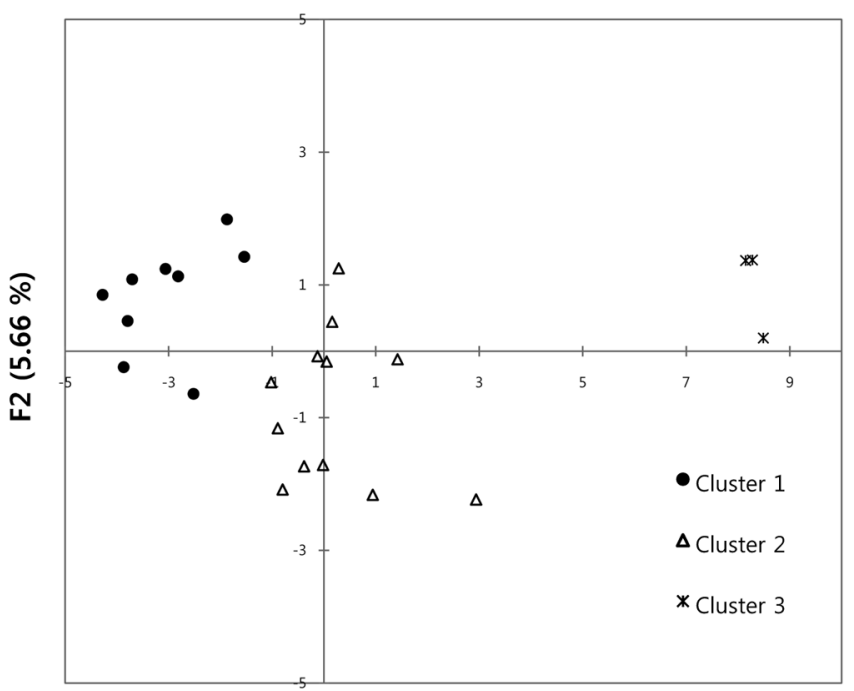

F1 (94.34 \%)

Fig. 3. Observations of 24 black raspberry wines based on their cluster by discriminant analysis.

고, 품질등급 분류를 위해 더 다양한 기법이 적용되어야 할 것으 로 여겨진다.

\section{요 약}

수도권 거주 소비자 100 명을 대상으로 전국에서 시판되는 24 종의 복분자주의 소비자 기호도 조사를 실시하였다. 24개 복분자 주 시료의 전반적인 기호도 평가의 분산분석을 통해 기호도 평 가에 연령 및 성별간의 차이보다는 개인 간의 차이가 더 크게 작 용한 것으로 나타났다. 전체 소비자 기호도 평가 결과를 바탕으 로 군집분석을 실시하여 시료 간 유사한 기호도 평가를 보인 세 개의 군집으로 분류하였다. 세 개의 군집은 기호척도의 빈도수 분포와 실제 기호도 평균 점수에서 군집 간의 차이가 확인되었 다. 이러한 군집 분류를 바탕으로 판별분석을 활용하여 군집의 분류가 적절한지 또한 판별함수의 예측력은 적정한지 파악하였 다. 판별분석결과 분류율이 $100 \%$ 로 적절한 예측력을 보였고, 세 군집간의 마할라노비스거리와 추출된 요인 내에서의 분포도도 적 정한 것으로 나타났다. 향후 다양한 우리술의 품질평가시스템 개 발에 소비자 기호도 조사를 활용한 평가방법이 활용 가능하리라 여겨진다.

\section{감사의 글}

본 연구는 2008년 고창군 연구개발비 용역 연구 사업으로 수 행되었으며 연구비 지원에 감사드립니다.

\section{References}

1. Drake MA. Invited review: Sensory analysis of dairy foods. J. Dairy Sci. 90: 4925-4937 (2007)

2. Kraggerud H, Solem S, Abrahamsen RK. Quality scoring - A tool for sensory evaluation of cheese? Food Qual. Prefer. 26: 221-230
(2012)

3. Cho SY, Seo G, Kim DH, Kim JH. Palatability grading analysis of Hanwoo beef using sensory properties and discriminant analysis. Korean J. Food Sci. Ani. Resour. 29: 132-139 (2009)

4. Bodyfelt FW, Drake MA, Rankin SA. Developments in dairy foods sensory science and education: From student contests to impact on product quality. Int. Dairy J. 18: $729-734$ (2008)

5. Hopfer H, Heymann H. Judging wine quality: Do we need experts, consumers or trained panelists? Food Qual. Prefer. 32: 221-233 (2014)

6. Delgado C, Guinard JX. How do consumer hedonic ratings for extra virgin olive oil relate to quality ratings by experts and descriptive analysis ratings? Food Qual. Prefer. 22: 213-225 (2011)

7. Guinard JX, Yip D, Cubero E, Mazzucchelli R. Quality ratings by experts, and relation with descriptive analysis ratings: a case study with beer. Food Qual. Prefer. 10: 59-67 (1998)

8. Ismail B, Haffar I, Baalbaki R, Henry J. Development of a total quality scoring system based on consumer preference weightings and sensory profiles: application to fruit dates (Tamr). Food Qual. Prefer. 12: 499-506 (2001)

9. Logue AW, Smith ME. Prediction of food preferences in adult humans. Appetite 7: 109-125 (1986)

10. Lyon DH. Factors affecting the sensory quality of vegetables. Food Sci. Technol. Today 4: 40-44 (1990)

11. Watson R, Gee A, Polkinghorne R, Porter M. Consumer assessment of eating quality - development of protocols for meat standards Australia (MSA) testing. Aust. J. Exp. Agr. 48: 1360-1367 (2008)

12. Perry D, Thomson JM, Hwang IH, Butchers A, Egan AF. Relationship between objective measurements and taste panel assessment of beef quality. Aust. J. Exp. Agr. 41: 981-989 (2001)

13. Poste LM, Butler G, Mackie D, Agar VE, Thompson BK, Cliplef RL, Mckay RM. Correlations of sensory and instrumental meat tenderness values as affected by sampling techniques. Food Qual. Prefer. 4: 207-214 (1993)

14. Thompson JM. Polkinghorne R, Hwang IH, Gee AM, Cho SH, Park BY, Lee JM. Beef quality grades as determined by Korean and Australian consumers. Aust. J. Exp. Agr. 48: 1380-1386 (2008)

15. Polkinghorne RJ, Nishimura T, Neath KE, Watson R. Japanese consumer categorisation of beef into quality grades, based on meat standards Australia methodology. Anim. Sci J. 82: 325-333 (2011)

16. Korea alcohol liquor industry association. Currents in domestic alcoholic beverage market. Alcohol Beverage News 3: 11 (2011)

17. Jung JW, Son MY, Jung SW, Nam PW, Sung JS, Lee SJ, Lee KG. Antioxidant properties of Korean black raspberry wines and their apoptotic effectson cancer cells. J. Sci. Food Agr. 89: 970977 (2009)

18. Macfie HJ, Bratchell N, Greenhoff K, Vallis LV. Designs to balance the effect of order of presentation and first-order carry-over effect in hall tests. J. Sens. Stud. 4:129-148 (1989)

19. Lee SJ, Lee KG. Understanding consumer preferences for rice wines using sensory data. J. Sci. Food Agr. 88: 690-698 (2008)

20. Martnez C, Santa-Cruz MJ, Hough G, Vega MJ. Preference mapping of cracker type biscuits. Food Qual. Prefer.13:535-544 (2002)

21. Monteleone E, Frewer L, Wakeling I, Mela DJ. Individual differences in starchy food consumption: The application of preference mapping. Food Qual. Prefer. 9:211-219 (1998)

22. Lee SJ, Noh WA, Choi YC. Sensory Evaluation of cooked rice with fuzzy reasoning. Korean J. Food Sci. Technol. 26: 776-780 (1994)

23. Kim JH, Kim JA. Statistical discriminant analysis on the driving ability of the brain-injured. J. Korean Data Info. Sci. Soc. 16: 1931 (2005) 